\title{
Factors influencing disability in patients with chronic low back pain attending a tertiary hospital in sub-Saharan Africa
}

\author{
Marie Doualla ${ }^{1,2,3}$, Jeannine Aminde ${ }^{1 *}$ (D), Leopold Ndemnge Aminde ${ }^{1,5}$, Fernando Kemta Lekpa ${ }^{1,3}$, \\ Felix Mangan Kwedi ${ }^{2,3}$, Emmanuel Vubo Yenshu ${ }^{4}$ and Alain Mefire Chichom ${ }^{1}$
}

\begin{abstract}
Background: Very little is known about the burden of chronic low back pain in Africa. This study aimed at assessing disability and associated factors in chronic low back patients in Cameroon.

Methods: We carried a hospital-based cross-sectional study including patients suffering from low back pain (LBP) of at least 12 weeks' duration. Disability was assessed using the Roland Morris Disability Questionnaire (RMDQ). RMDQ > 4 described persons with dysfunctional levels of disability.

Multivariable linear regression was used to investigate factors associated with higher RMDQ scores hence greater disability. Variables investigated included; gender, age, marital status, employment status and type, smoking history, alcohol consumption, income, pain intensity, LBP duration, psychological wellbeing, sleep satisfaction, leg pain, numbness/paresthesia, bowel/bladder dysfunction symptoms (BBDS), body mass index (BMI), and days of work absence.

Results: A sample of 136 adults (64\% female) with a mean age of $50.6 \pm 12.2$ years participated in the study. Median duration of LBP was 33 (25th - 75th percentile: 12-81) months. Mean RMDQ score was $12.8 \pm 6$. In multivariable linear regression, pain intensity $(\beta=0.07, p=0.002)$, longer days of work absence $(\beta=0.15, p=0.003)$ and $\operatorname{BBDS}(\beta=2.33, p=$ 0.029 ) were associated with greater disability. Factors such as consumption of alcohol $(\beta=-3.55, p=0.005)$ and higher psychological wellbeing scores ( $\beta=-0.10, p=0.004$ ) significantly contributed to less disability (lower RMDQ scores). Dysfunctional levels of disability were present in $88.1 \%$ of patients.

Conclusion: CLBP is associated with significant disability and this relationship is driven by several factors. Multidisciplinary management strategies especially those targeted to improve pain control, manage BBDS and improve psychological wellbeing could reduce disability and improve quality of life.
\end{abstract}

Keywords: Chronic low back pain, Disability, Africa

\section{Background}

LBP is described as "pain, muscle tension, or stiffness localized below the costal margin and above the inferior gluteal folds, with or without leg pain (sciatica), and is defined as chronic when it persists for 12 weeks or more" [1]. It is estimated that, at any point in time, about $11.9 \%$ of the world's population is suffering from LBP [2] . The prevalence of chronic LBP worldwide is estimated at $19.6 \%$ in those aged between 20 and 59 years [3].

\footnotetext{
* Correspondence: jeannineatemanyingu@rocketmail.com

${ }^{1}$ Faculty of Health Sciences, University of Buea, Buea, Cameroon

Full list of author information is available at the end of the article
}

In Africa, LBP is increasingly recognised as a major health problem. A systematic review of epidemiological studies across Africa reported a pooled adult prevalence of $32 \%$ with an average lifetime prevalence $62 \%$ [4]. This is higher than the $28.8 \%$ reported among adult Americans in 2013 [5]. In Cameroon, the prevalence of CLBP was 19.1\% among patients presenting for rheumatology consultations during 2004 to 2013 at the Douala General Hospital [6].

Interestingly, though a frequent cause of clinic visits, the specific aetiology of the pain in LBP is not often identified; in which case it is referred to as "non-specific LBP". Therefore, the first aim of the clinical evaluation is

(c) The Author(s). 2019 Open Access This article is distributed under the terms of the Creative Commons Attribution 4.0 International License (http://creativecommons.org/licenses/by/4.0/), which permits unrestricted use, distribution, and reproduction in any medium, provided you give appropriate credit to the original author(s) and the source, provide a link to the Creative Commons license, and indicate if changes were made. The Creative Commons Public Domain Dedication waiver (http://creativecommons.org/publicdomain/zero/1.0/) applies to the data made available in this article, unless otherwise stated. 
usually to situate the patient in one of three categories; non-specific low back pain, back pain with radiculopathy or stenosis, and back pain associated with another specific spinal cause [7]. It is equally considered important to identify in the patient any risk factors for progressing to chronic disability [7], LBP being a well-recognised disabling condition [8]. Disability refers to a restriction or lack of ability to perform an activity in the manner or within the range considered normal for a human being [9]. Disability is a core issue in LBP, affecting physical performance and consequently work productivity [10].

According to the Global Burden of Disease (GBD) 2015 study, LBP is the leading cause of disability worldwide, accounting for 815 Years Lived with Disability (YLD) per 100,000 populations. This value represents a $17.2 \%$ increase since 2005 [8]. This study reported that lower back and neck pain grouped, constituted the leading cause of disability in all high-income countries, and in almost all Latin American, Asian, and Middle Eastern countries.

In Sub-Saharan Africa (SSA), a Ugandan hospital based cross-sectional described significant disability in LBP patients with $87 \%$ of participants reporting up to 14 days of work loss due to LBP [11]. In nine of the countries in this region, LBP and neck pain are recognized as the leading causes of YLD (2). Cameroon is one of these nine and LBP is also the first cause of rheumatologic consultation [6].

A number of methods assessing disability in LBP have been described in the literature, broadly classified as self-report or performance-based measures. Performancebased tests like the Isernhagen Work Systems Functional Capacity Evaluation (IWS-FCE) are thought to provide an objective representation of a patient's functional capacity $[12,13]$, and hence are frequently used in rehabilitation medicine. On the other hand, self-report tools (mostly questionnaires) are more practical, inexpensive and are widely used in CLBP research. The RMDQ is a self-report back pain specific disability tool that measures limitation in activities of daily living. It has been found sensitive and reliable [14], and has been validated in patients with low back pain across different settings including West African communities [15]. It is the second most widely used tool of its kind after the Oswestry Disability Questionnaire. In comparison to the Oswestry tool, the RMDQ has been found simpler to use, readily understood with similar psychometric properties [16-18].

Studies in Brazil $(17,18)$ and in Egypt $[21]$ among patients with CLBP have reported mean RMDQ scores generally above 14 (out of the total score of 24). However, in a study in Netherland a slightly lower score (12.6) was reported in patients in a pain management centre [22].

Core muscle dysfunction is believed to be a major trigger for low back pain [23, 24]. These muscles are responsible for maintaining spine stability and counteracting external forces. Weakness results in instability and strain on the vertebral column and intervertebral discs [23]. Core muscle dysfunction has equally been associated with more severe pain and greater disability in LBP patients $[24,25]$.

Like core muscle dysfunction, impaired psychological wellbeing and impaired sleep quality are recognized risk factors of LBP (and possibly also consequences of the pain), while equally prolonging disability in these patients [26-28]. Fear of movement from fear of the pain or re-injury results in muscle disuse and structural changes, hence another cause of prolonged disability in LBP $[27,29,30]$. More so, leg pain, back tenderness, lack of exercise and advancing age have equally been associated with greater disability in LBP $[30,31]$.

In Cameroon, there are no published studies exploring disability among CLBP patients. This represents an immense knowledge gap that this study sought to fill. The purpose of this study was thus to assess the level of and factors associated with disability among patients with CLBP. Our goal was to provide a better understanding of the factors that contribute to disability in CLBP patients in Cameroon in order to inform management strategies.

\section{Methods}

\section{Study design and setting}

This was a cross-sectional study conducted during January to March 2017 at the Rheumatology unit of the Douala General Hospital (DGH) in Cameroon. Three rheumatologists (who actually made or confirmed the diagnoses for patients in the study) are responsible for this unit. The unit runs outpatient consultations from Monday to Friday. Each rheumatologist has two consultation days, with an average of 1 or 2 rheumatologists consulting daily. Each rheumatologist consults approximately $15-30$ patients a day, $20-40 \%$ of which are low back pain patients presenting either de novo or for follow-up visits. DGH is a tertiary referral and teaching hospital receiving patients from all ten regions in Cameroon and surrounding African countries. Douala, the economic capital is the most populated city of Cameroon with an estimated population of $2,768,400$ in 2015 [32].

\section{Sampling and study participants}

We consecutively included adult patients aged 18-70 years with LBP of at least 12 weeks' duration who presented de novo or for follow up visits during the study period. LBP was defined as: sensations of pain, muscle tension, or stiffness, localized below the costal margin and above the inferior gluteal folds. The area involved identified on a human diagram. Patients with pregnancy, and suspicion of cauda equina syndrome, recent trauma or LBP surgical emergencies, and patients unable to comprehend questions were excluded. 


\section{Study procedures and data collection}

Eligible and consenting participants were invited to complete an interviewer-administered semi-structured questionnaire. This was available in English and French (the two official languages in Cameroon) to serve participants expressing themselves in either language. Data on general characteristics obtained included; gender, age, marital status (single, married or widowed), employment status (employed, housewife, student, unemployed or retired), employment type (physical labour, non-physical labour), smoking history (current smoker, former smoker and non-smoker), alcohol consumption (consumer or non-consumer), quantity of alcohol consumed (expressed in units per week). An "alcohol consumer" was considered to be a study participant who admitted to consuming at least one alcoholic drink in the month preceding the interview. Other data included level of education (no education, primary, secondary and tertiary education) and average monthly income $(<50,000$ FCFA, 50000-100000FCFA, 100,000-300,000 FCFA, > 300,000 FCFA [1US\$ $=530$ FCFA $]$ ).

\section{Assessment of disability}

Disability was assessed using the Roland Morris Disability Questionnaire (RMDQ), a 24-item LBP-specific tool that assesses impairment in activities of daily living. The RMDQ was chosen for its low administrative burden, easy comprehensibility, proven high responsiveness and sensitivity in LBP, and the availability of validated versions in English and French [33]. It is scored from zero to 24 , with higher scores implying greater disability. In this study, we further categorized participants as dysfunctional (RMDQ score $>4$ ) or functional (RMDQ score $\leq 4)$. A score of four is a proposed cut-off to classify LBP patients as functional or dysfunctional [34], and is supported by the findings of other authors [35].

\section{Other clinical characteristics}

Pain intensity was measured with a $100 \mathrm{~mm}$ visual analogue scale (VAS). Participants were required to report the total duration of their CLBP by answering the question; "For how long have you had an ongoing low back pain problem?", adapted from the recommendations of the CLBP Research Task Force of the American National Institute of Health Pain Consortium [36]. They equally reported the duration of the current pain symptoms/episode by answering the question "How long has it been since you went for a whole month without low back pain?", based on the definition of a LBP episode by Vet et al. [37]. This was done in an effort to clearly characterize the duration of pain, taking into account the challenges that exist due to the often intermittent, recurring nature of $\mathrm{LBP}$, and considering the ambiguity in existing LBP terminology. Participants were asked to report the presence or absence of certain symptoms; leg pain, numbness/paresthesia in lower limbs (any of; tingling, burning, electric-currents, numbness, pins and needles); BBDS or bladder/bowel dysfunction symptoms (any of; uncontrollable urges to urinate or stool, urine or stool leakages; straining unduly when stooling or initiating urine).

Psychological wellbeing of participants was assessed using the psychological domain score of the World Health Organization Quality of Life brief tool (WHOQOL-BREF). This is a generic tool that assesses quality of life with six measures. The psychological domain score is computed by summing scores of seven specific items covering bodily image and appearance, negative feelings like anxiety and depression, positive feelings, self-esteem, spirituality/religion/personal beliefs, and thinking, learning, memory and concentrations. The summed score is transformed to a scale of 0-100 using the steps described in the WHOQOL manual [38], with higher scores indicating greater wellbeing.

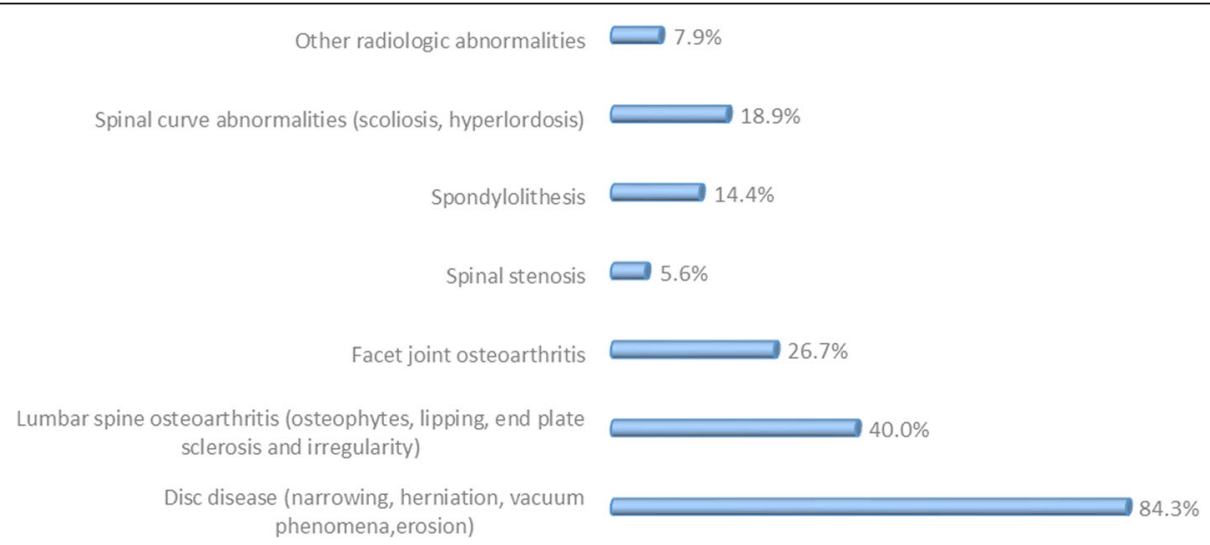

Fig. 1 Specific diagnoses of patients with CLBP. Legend: Bar chart showing the different aetiological diagnoses of patients with CLBP. The percentages next to the bars represent the proportion of each diagnosis in the cohort of patients. 
Sleep satisfaction was assessed by asking patients to rate their satisfaction with their sleep in the past month on a scale of 1 to 5 ( 1 representing 'very dissatisfied' and 5 representing 'very satisfied'). This was expressed as a percentage score.

Patients' weight and height were also measured. This was done with participants wearing light clothing and without shoes; their weight was measured using $\mathrm{Seca}^{\circ}$ scales while height was measured with the adult Leicester ${ }^{\circ}$ stadiometer. The stadiometers were placed against the wall, while participants stood upright without their shoes and their heels and occiput on the stadiometer. For height, measures were to the nearest $0.5 \mathrm{~cm}$ while for weight we considered one decimal place. Their hospital medical records were reviewed to collect information on radiologic findings and treatment.

Work absence due to $L B P$ was denoted "days of work loss" and defined as the number of days of restricted routine activity (inability to carry out your regular activities) or absence at workplace because of CLBP occurring within the 30 days preceding the interview.

\section{Ethical considerations}

This study received Ethical Approval from the Faculty of Health Sciences Institutional Review Board (2017/003/UB/ SG/IRB/FHS). The components and purpose of the study were explained to all potential study participants and only those who freely gave written consent were included. Patient confidentiality was maintained and the study adhered to the World Medical Association's Declaration of Helsinki.

\section{Data management and statistical analysis}

Data were analyzed using the Statistical Package for Social Sciences (SPSS Inc., Chicago, Illinois, USA) version 20. Results are summarized as counts and percentages for categorical variables and as means and standard deviation (SD) or median with 25th and 75th percentiles where appropriate for continuous variables. Standard assumptions of parametric tests (e.g. linearity, normality of residuals, homoscedasticity) were tested; as such, we performed no data transformations. The RMDQ score was analyzed as a continuous outcome variable. We adopted a threshold score of $\geq 4$ to report prevalence of dysfunctional CLBP, based on a previous study conducted among adult LBP patients [34]. Bivariate analysis was performed to investigate significant associations with RMDQ scores/disability. Pearson's correlation was used for continuous variables and for categorical variables, the independent samples t-test was used to test the group differences in mean RMDQ scores and in case of more than two groups, analysis of variance (ANOVA) was used. Variables that were significant, or trending towards $(p<0.1)$ in bivariate analysis, were then fitted in a multivariable linear regression model to determine factors independently associated with disability. Prior to fitting the multivariable model, we checked for evidence of multicollinearity in the independent variables via a correlation matrix and then ran collinearity diagnostics to assess their tolerance and variance inflation factors (VIF). All VIFs were less than 2, suggesting absence of any multicollinearity. Statistical significance was set at $p<0.05$.

Table 1 General characteristics of the study population

\begin{tabular}{|c|c|c|c|}
\hline Variable & Category & $n$ & $\%$ \\
\hline \multirow[t]{2}{*}{ Gender } & Male & 48 & 35.6 \\
\hline & Female & 87 & 64.4 \\
\hline \multirow[t]{3}{*}{ Marital Status } & Married & 97 & 73 \\
\hline & Single & 24 & 18.0 \\
\hline & Widowed & 12 & 9.0 \\
\hline \multirow[t]{4}{*}{ Educational level } & No formal & 2 & 1.5 \\
\hline & Primary & 32 & 23.5 \\
\hline & Secondary & 54 & 39.7 \\
\hline & Tertiary & 48 & 35.3 \\
\hline \multirow[t]{5}{*}{ Employment status } & Unemployed & 14 & 10.4 \\
\hline & Employed & 95 & 71.1 \\
\hline & Student & 3 & 2.2 \\
\hline & Housewife & 13 & 9.6 \\
\hline & Retired & 9 & 6.7 \\
\hline \multirow[t]{3}{*}{ Employment type } & Physical labour & 26 & 27.1 \\
\hline & Non-physical & 66 & 68.8 \\
\hline & Combination & 4 & 4.2 \\
\hline \multirow[t]{4}{*}{ Income level (FCFA) } & $<50,000$ & 56 & 41.5 \\
\hline & $50,000-100,000$ & 18 & 13.3 \\
\hline & $100,000-300,000$ & 28 & 20.7 \\
\hline & $>300,000$ & 33 & 24.4 \\
\hline \multirow[t]{2}{*}{ Alcohol } & Non-consumer & 27 & 19.9 \\
\hline & Consumer & 109 & 80.1 \\
\hline \multirow[t]{3}{*}{ Smoking } & Non-smoker & 112 & 82.4 \\
\hline & Former & 21 & 15.4 \\
\hline & Current & 3 & 2.2 \\
\hline \multirow[t]{2}{*}{ Sensory neuropathy } & Absent & 67 & 49.3 \\
\hline & Present & 69 & 50.7 \\
\hline \multirow[t]{2}{*}{$B B D S$} & Absent & 90 & 66.2 \\
\hline & Present & 46 & 33.8 \\
\hline \multirow[t]{2}{*}{ Leg pain } & Absent & 59 & 43.4 \\
\hline & Present & 77 & 56.6 \\
\hline \multirow[t]{2}{*}{ Treatment } & No & 22 & 16.7 \\
\hline & Yes & 110 & 83.3 \\
\hline
\end{tabular}

$B B D S=$ Bowel/bladder dysfunction symptoms, FCFA = Central African Franc 
Table 2 Correlations between continuous variables and RMDQ scores in patients with CLBP at the Douala General Hospital, Cameroon

\begin{tabular}{llll}
\hline Variables & $\begin{array}{l}\text { RMDQ score } \\
\text { mean } \pm \text { SD }\end{array}$ & $r$ & $p$-value \\
\hline Age in years & $50.6 \pm 12.2$ & 0.27 & 0.002 \\
$\begin{array}{l}\text { Duration of CLBP in } \\
\text { months, median (IQR) }\end{array}$ & $33.0(69.0)$ & 0.09 & 0.305 \\
$\begin{array}{l}\text { Duration of current pain } \\
\text { episode in months, }\end{array}$ & $12.0(21.0)$ & 0.18 & 0.034 \\
median (IQR) & & & \\
$\begin{array}{l}\text { Pain intensity } \\
\text { Days of work loss }\end{array}$ & $41.3 \pm 24.3$ & 0.45 & $<0.0001$ \\
$\begin{array}{l}\text { Units of Alcohol } \\
\text { per week }\end{array}$ & $5.5 \pm 11.7$ & 0.36 & $<0.0001$ \\
BMl (kg/m ${ }^{2}$ ) & & -0.02 & 0.835 \\
Sleep satisfaction & $29.6 \pm 5.7$ & -0.01 & 0.942 \\
Psychological wellbeing & $59.0 \pm 22.5$ & -0.19 & 0.030 \\
\hline
\end{tabular}

$S D=$ standard deviation, $r=$ Pearson's correlation coefficient, $I Q R=$ interquartile range, $B M I=$ body mass index,$R M D Q=$ Roland Morris Disability Questionnaire

\section{Results}

\section{General characteristics}

A sample of 136 CLBP (64\% females) was included. Forty-one percent of participants had non-specific CLBP, $56 \%$ CLBP with radiculopathy/stenosis, and 3\% had CLBP from a specific spinal cause. The principal specific aetiologies encountered in participants are described in Fig. 1. The mean age was 58.7 years. Seventy-three percent were married and about two-thirds $(65 \%)$ had secondary education level or less. Most (71\%) were employed, and work type generally involved no physical labour (69\%). Forty-five percent of participants earned $>100,000$ FCFA (>190\$), Table 1 .

\section{Pain, disability and work loss}

The median (IQR) duration of CLBP was 33.0 (69) months. The median duration of current pain symptoms was 12 months and median pain intensity was $40 \mathrm{~mm}$ (39). The mean disability score was $12.5 \pm 6$. RMDQ $>4$ was found in $88.1 \%$ of participants. Average work lost days was $6 \pm 10$ days in the previous month due to LBP (Table 2).

\section{Factors influencing disability}

On bivariate analysis (Table 2), longer work absence (Fig. 2) and greater pain intensity (Fig. 3), moderately correlated with higher disability scores $(r=0.36, p<$ 0.001 and $r=0.45, \mathrm{p}<0.001$ respectively). There were weak positive relationships between duration of the current pain episode $(r=0.18, p=0.034)$, patients age ( $r$ $=0.27, p=0.002)$ with disability. However, sleep satisfaction $(r=-0.19, \mathrm{p}=0.03)$ and psychological wellbeing $(r$ $=-0.40, \mathrm{p}<0.001)$ negatively correlated with disability scores (Table 2 and Fig. 4).

As stated we used One-way ANOVA and employed the Tukey post hoc criterion for significance. Our findings indicated that the mean RMDQ was significantly higher in the widowed $(16.9 \pm 4.6)$ when compared to the married $(12.5 \pm 6.1)$ or single $(11.5 \pm 6.3)$; and in persons with no formal education when compared to those with tertiary education $(23.0 \pm 1.4$ vs. $11.3 \pm 5.6)$. Non-consumers of alcohol; persons with BBDS; and those with leg pain equally had higher mean RMDQ

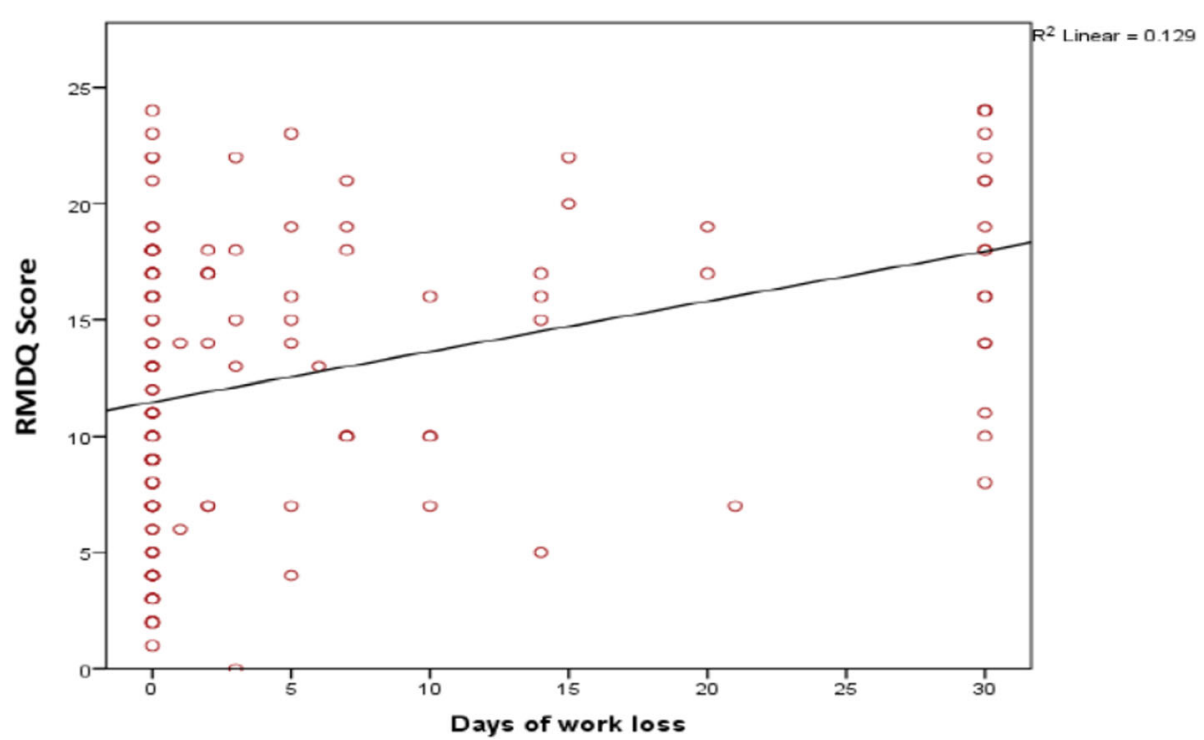

Fig. 2 Correlation between RMDQ scores and days of work loss. Legend: Scatter plot showing correlation between disability (RMDQ scores) and days of work loss. The many small circles represent the plotted values obtained for each of the variables while the line represents the best fit for the correlation between them. 


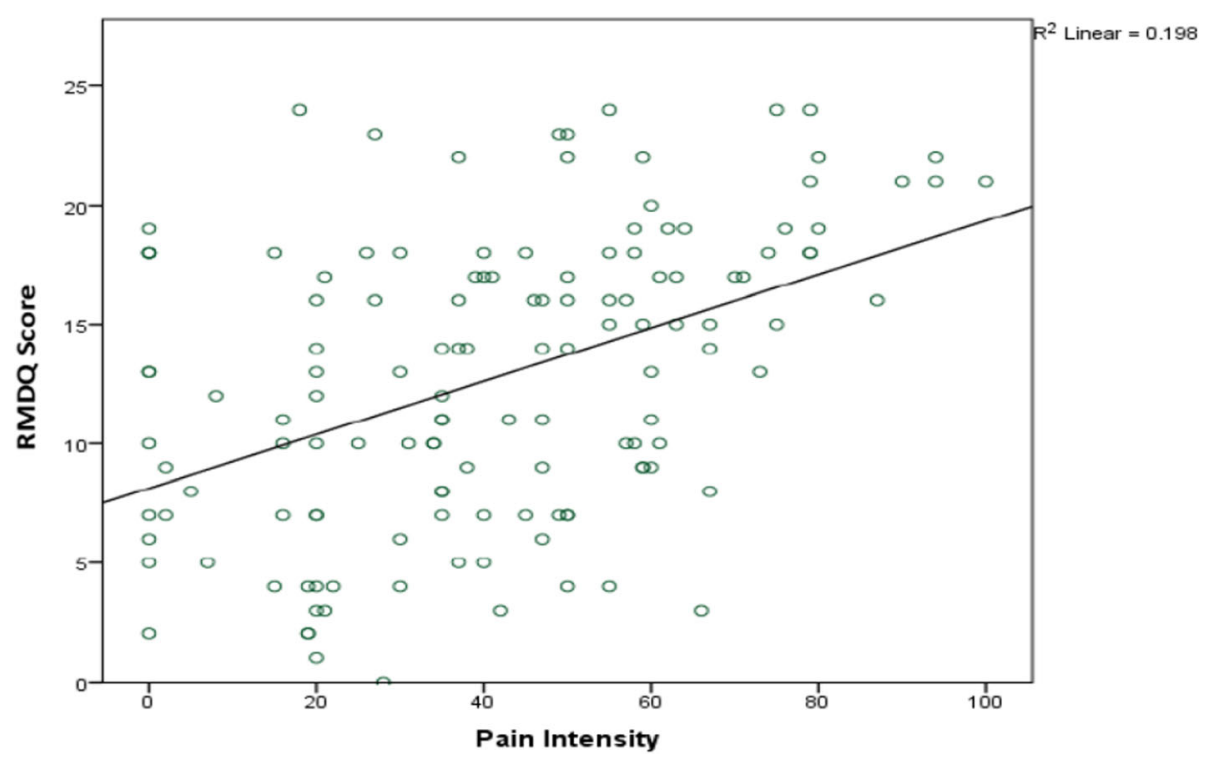

Fig. 3 Correlation between RMDQ scores and pain intensity. Legend: Scatter plot showing relationship between disability (RMDQ scores) and pain intensity scores measured with visual analogue scale (VAS).The many small circles represent the plotted values obtained for each of the variables while the line represents the best fit for the correlation between them.

scores when compared with counterparts without (Table 3). Alcohol consumption (Fig. 5) and BBDS (Fig. 6) had the greatest impact on the RMDQ $(p<0.01)$.

In the multivariable linear regression model, the factors that were independently associated disability were; pain intensity ( $\beta=0.07, p=0.002)$, days of work absence $(\beta=0.15$, $p=0.003)$, psychological wellbeing $(\beta=-0.10, p=0.004)$, alcohol consumption $(\beta=-3.55, p=0.005)$, and bowel/ bladder dysfunction $(\beta=2.33, p=0.029)$, Table 4 . The model explained $40.7 \%$ of the variance in disability scores.

\section{Discussion}

The aim of this study was to describe the level of disability and associated factors among individuals with CLBP in Cameroon. In this hospital-based study, we found that more than $80 \%$ of CLBP patients had significant

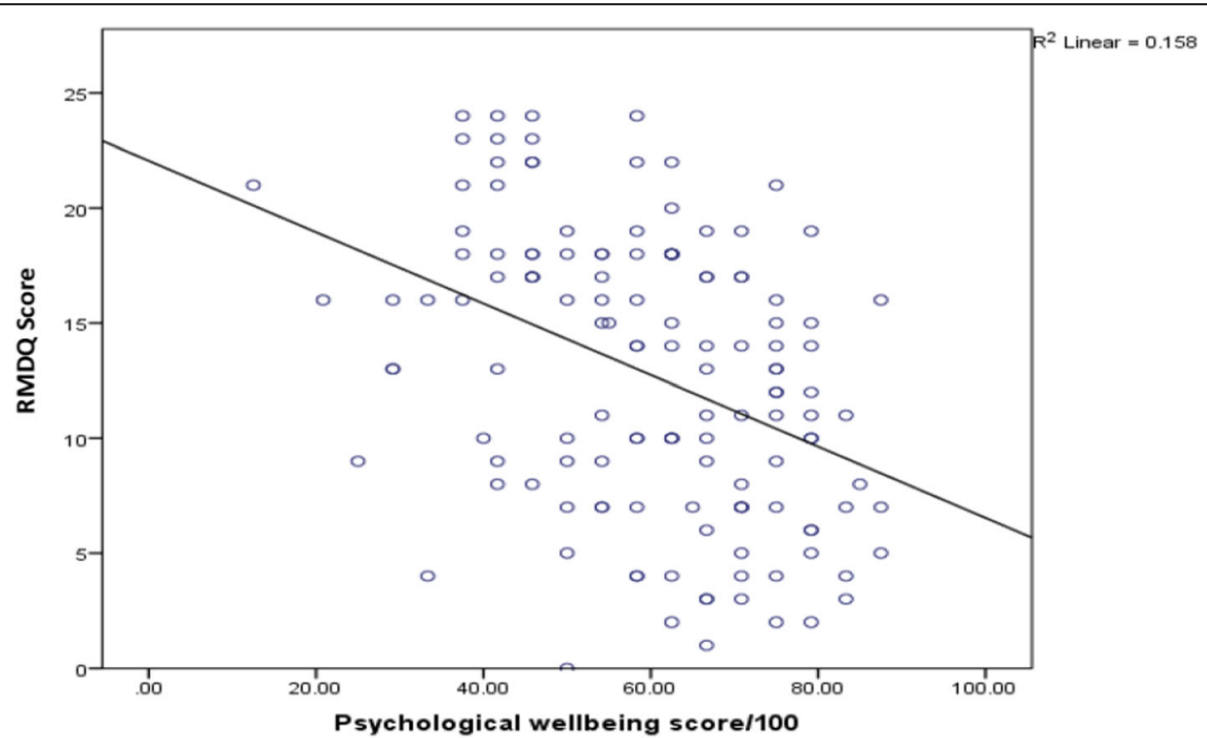

Fig. 4 Correlation between RMDQ scores and psychological wellbeing. Legend: Scatter plot showing correlation between disability (RMDQ scores) and psychological wellbeing scores. The many small circles represent the plotted values obtained for each of the variables while the line represents the best fit for the correlation between them. 


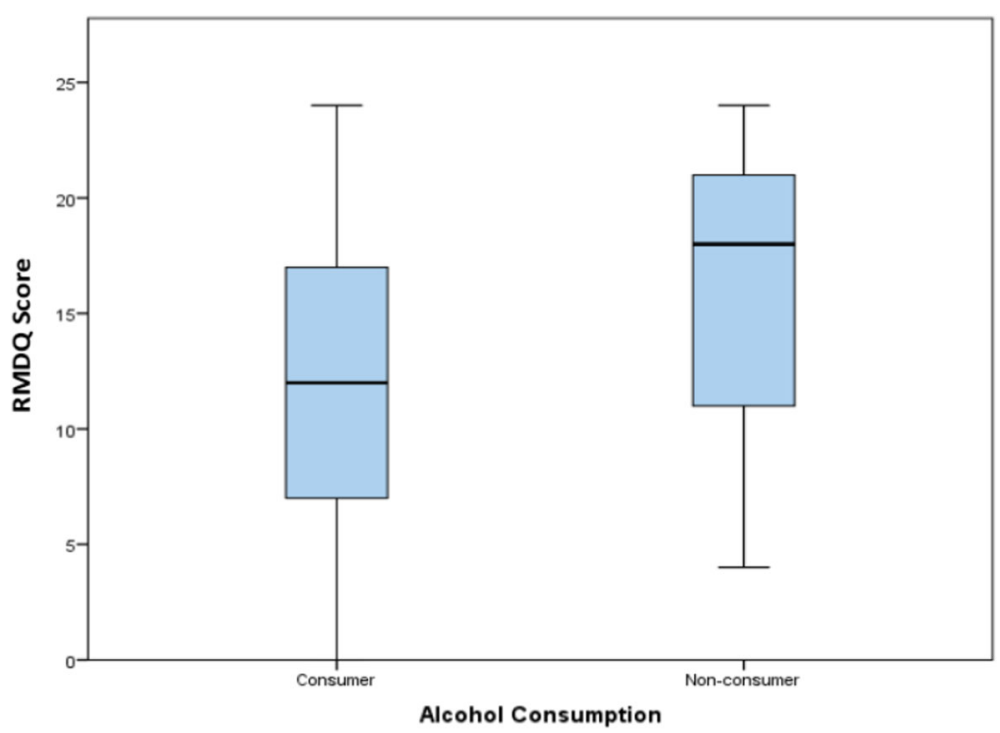

Fig. 5 RMDQ score variation between alcohol consumers and non-consumers. Legend: Box plots showing differences in disability (RMDQ scores) by alcohol consumption status. The horizontal line in the box represents the median RMDQ score, while the lower and upper edges of the boxes represent the 25th and 75th percentiles (and interquartile range being the difference between them).The tip of the extended vertical lines on either sides of the boxes refer to the minimum and maximum RMDQ scores.

disability. Affected individuals reported on average six days of absence from work in previous month due to their back pain thus suggesting that CLBP has a considerable impact on productivity. Factors independently associated with disability in our cohort of CLBP patients were present pain, days of work absence, psychological wellbeing, alcohol consumption and BBDS.

The mean RMDQ score in our study was 12.8 which was over 3 times the cut off for dysfunctionality proposed by Stratford and Riddle [34]. Four out of five participants had dysfunctional LBP. CLBP patients in Cameroon therefore, have high levels of functional impairment and the level of disability is consistent with findings in other settings $[19,20,22,27,39]$. Our results support the likely validity and applicability of the RMDQ score in the Cameroonian context.

Absence from work or restriction of routine activity is a major cause of reduced productivity and economic loss

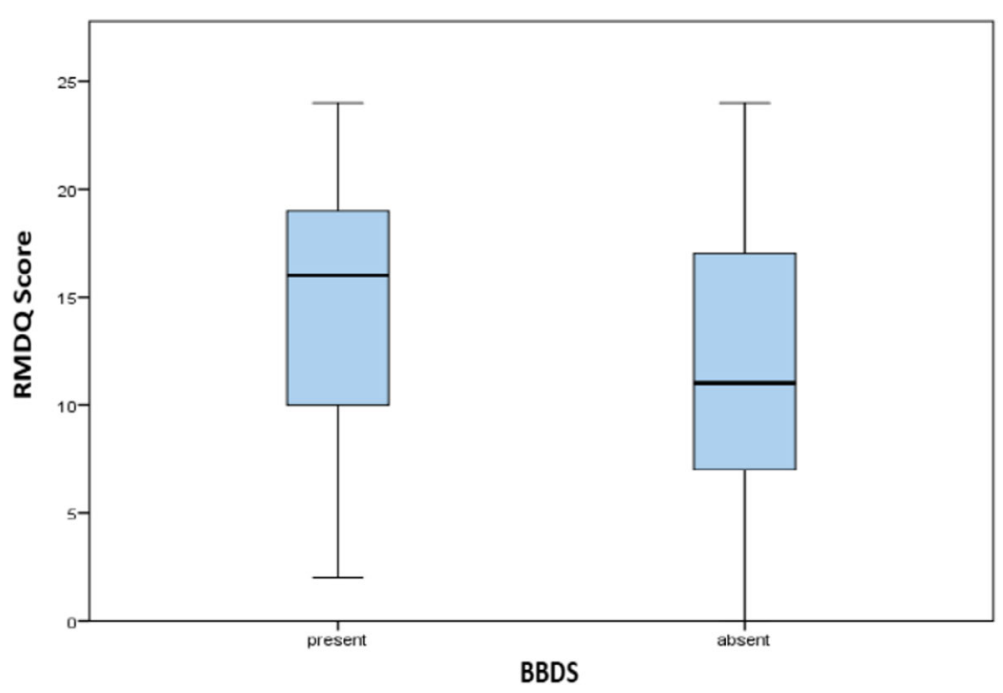

Fig. 6 RMDQ score variation between persons with and without BBDS. Legend: Box plots showing differences in disability (RMDQ scores) in those with and without bowel/bladder dysfunction symptoms (BBDS). The horizontal line in the box represents the median RMDQ score, while the lower and upper edges of the boxes represent the 25th and 75th percentiles (and interquartile range being the difference between them).The tip of the extended vertical lines on either sides of the boxes refer to the minimum and maximum RMDQ scores. 
Table 3 RMDQ score variations by sociodemographic and clinical characteristics of patients with CLBP at the Douala General Hospital, Cameroon

\begin{tabular}{|c|c|c|c|c|}
\hline Variable & Category & $\begin{array}{l}\text { RMDQ score } \\
\text { mean } \pm S D\end{array}$ & t or F statistic & $p$-value \\
\hline \multirow[t]{2}{*}{ Gende } & Male & $11.6 \pm 6.4$ & -1.71 & 0.090 \\
\hline & Female & $13.5 \pm 5.9$ & & \\
\hline \multirow[t]{3}{*}{ Marital Status } & Married & $12.5 \pm 6.1^{\mathrm{a}}$ & 3.45 & 0.035 \\
\hline & Single & $11.5 \pm 6.3^{\mathrm{a}}$ & & \\
\hline & Widowed & $16.9 \pm 4.6^{b}$ & & \\
\hline \multirow[t]{4}{*}{ Educational level } & No formal & $23.0 \pm 1.4^{\mathrm{a}}$ & 3.67 & 0.014 \\
\hline & Primary & $14.3 \pm 5.3$ & & \\
\hline & Secondary & $12.9 \pm 6.7$ & & \\
\hline & Tertiary & $11.3 \pm 5.6^{b}$ & & \\
\hline \multirow{5}{*}{$\begin{array}{l}\text { Employment } \\
\text { status }\end{array}$} & Unemployed & $14.2 \pm 6.5$ & 3.25 & 0.014 \\
\hline & Employed & $11.7 \pm 5.8$ & & \\
\hline & Student & $13.3 \pm 6.0$ & & \\
\hline & Housewife & $15.9 \pm 6.6$ & & \\
\hline & Retired & $17.4 \pm 5.4$ & & \\
\hline \multirow[t]{3}{*}{ Employment type } & Physical labour & $13.1 \pm 6.8$ & 1.18 & 0.313 \\
\hline & Non-physical & $11.1 \pm 5.4$ & & \\
\hline & Combination & $12.8 \pm 5.9$ & & \\
\hline \multirow{4}{*}{$\begin{array}{l}\text { Income level } \\
\text { (FCFA) }\end{array}$} & $<50,000$ & $13.6 \pm 6.3$ & 0.78 & 0.507 \\
\hline & $50,000-100,000$ & $12.8 \pm 5.2$ & & \\
\hline & $\begin{array}{l}100,000- \\
300,000\end{array}$ & $11.4 \pm 5.9$ & & \\
\hline & $>300,000$ & $12.4 \pm 6.6$ & & \\
\hline \multirow[t]{2}{*}{ Alcohol } & Non-consumer & $16.2 \pm 5.7$ & -3.31 & 0.001 \\
\hline & Consumer & $11.9 \pm 5.9$ & & \\
\hline \multirow[t]{3}{*}{ Smoking } & Non-smoker & $12.7 \pm 5.9$ & 0.53 & 0.592 \\
\hline & Former & $12.9 \pm 7.0$ & & \\
\hline & Current & $16.3 \pm 8.6$ & & \\
\hline \multirow{2}{*}{$\begin{array}{l}\text { Sensory } \\
\text { neuropathy }\end{array}$} & Absent & $11.8 \pm 6.3$ & -1.93 & 0.055 \\
\hline & Present & $13.8 \pm 5.9$ & & \\
\hline \multirow[t]{2}{*}{$B D D S$} & Absent & $11.8 \pm 5.9$ & -2.67 & 0.008 \\
\hline & Present & $14.7 \pm 6.2$ & & \\
\hline \multirow[t]{2}{*}{ Leg pain } & Absent & $11.6 \pm 6.4$ & -2.06 & 0.041 \\
\hline & Present & $13.7 \pm 5.8$ & & \\
\hline \multirow[t]{2}{*}{ Treatment } & No & $10.6 \pm 6.4$ & 1.84 & 0.68 \\
\hline & Yes & $13.2 \pm 6.0$ & & \\
\hline
\end{tabular}

$\overline{a-b}=$ Means in a category with unidentical superscript letters differ $(P<0.05)$, using Tukey post-hoc criterion

associated with LBP. We observed that CLBP accounted for over six days of absence from work in a month amongst our patients. In Taiwan a mixed cohort of acute and chronic LBP patients in ambulatory clinics reported $4.6 \pm 8.4$ days [39], thus in line with our results. In Uganda, the impact was higher, with up to 14 days of work loss reported in CLBP patients [11].

In a WHO multinational Study on Global Aging and Adult Health (SAGE), pain intensity was independently predictive of disability in aged adults with LBP [31]. Similarly, in Brazilian CLBP patients, pain intensity showed low to moderate correlations with the RMDQ score [20]. Mirroring these findings, pain significantly contributed to disability in our patients. However, the variability in our disability score was influenced more by alcohol consumption, sphincter dysfunction and work absence. The relationship between alcohol consumption and disability appears ambiguous. Alcohol consumption did not affect disability in the SAGE study. However, similar to our findings, a one-year cohort study exploring factors associated with disability in patients with radicular LBP found that non-consumption of alcohol was associated with greater disability [30].

Approximately one third of LBP patients have been found to have sphincter dysfunction [40, 41]. However, its contribution to disability in these patients has not yet been elaborately explored. Evidence from one study found that LBP patients with higher levels of disability were more likely to suffer urinary incontinence [40]. Our findings confirm this and demonstrate that difficulty with urinary or faecal control has a significant effect on disability in LBP.

Psychological factors are known to influence disability in $\operatorname{LBP}[19,22,27,42,43]$. We observed a moderate-to-strong correlation between psychological wellbeing and disability. Furthermore, poor sleep quality has been clearly implicated in increased pain related-disability [26, 44]. In our study, this relationship was significant only in bivariate analysis.

This study had a number of limitations. First, the use of a cross-sectional study design limited the establishment of temporality or causal relationships, which would have been possible with a prospective cohort design. However, our study revealed associations that can serve as benchmark in the design of future studies. Secondly, our study may be prone to selection bias owing to the non-random sampling and hospital-based nature of the study. It is thus likely that our findings may not reflect the situation of CLBP patients at other health facilities across the county. Interpretation of our results in terms of generalizability must therefore be done with caution.

Nevertheless, we have used rigorous statistical methods to explore the burden and factors associated with disability in patients with chronic low back pain. Our study to the best of our knowledge is the first in Cameroon to investigate the disability and chronic low back pain relationship and thus may serve as framework for further research.

\section{Conclusion}

Evidence from this study has confirmed that CLBP is associated with significant disability and work loss. Improved psychological wellbeing was associated with less 
Table 4 Multivariable linear regression showing factors independently associated with disability (RMDQ score) in patients with CLBP, Douala General Hospital, Cameroon

\begin{tabular}{|c|c|c|c|c|}
\hline Variables & Categories & $\beta$ & $95 \% \mathrm{Cl}$ & $p$-value \\
\hline \multirow[t]{3}{*}{ Marital Status } & Single & -1.31 & -4.21 to 1.58 & 0.371 \\
\hline & Widowed & 3.42 & -0.14 to 6.98 & 0.059 \\
\hline & Married & 1 & & \\
\hline \multirow[t]{2}{*}{ Gender } & Female & -0.05 & -2.12 to 2.02 & 0.963 \\
\hline & Male & 1 & & \\
\hline \multirow[t]{4}{*}{ Educational level } & Tertiary & -1.28 & -9.55 to 6.99 & 0.759 \\
\hline & Secondary & -2.49 & -10.85 to 5.86 & 0.555 \\
\hline & Primary & -1.98 & -10.26 to 6.31 & 0.637 \\
\hline & No formal & 1 & & \\
\hline \multirow[t]{5}{*}{ Employment status } & Retired & -0.90 & -5.87 to 4.08 & 0.721 \\
\hline & Employed & 0.15 & -3.13 to 3.43 & 0.929 \\
\hline & Student & -0.59 & -8.08 to 6.91 & 0.877 \\
\hline & Housewife & 0.62 & -3.83 to 5.06 & 0.784 \\
\hline & Unemployed & 1 & & \\
\hline \multirow[t]{2}{*}{ Alcohol } & Consumer & -3.55 & -6.01 to -1.10 & 0.005 \\
\hline & Non-consumer & 1 & & \\
\hline \multirow[t]{2}{*}{ Sensory neuropathy } & Present & 0.67 & -1.35 to 2.70 & 0.510 \\
\hline & Absent & 1 & & \\
\hline \multirow[t]{2}{*}{ Sphincter Dysfunction } & Present & 2.33 & 0.25 to 4.42 & 0.029 \\
\hline & Absent & 1 & & \\
\hline \multirow[t]{2}{*}{ Leg pain } & Present & 0.51 & -1.49 to 2.52 & 0.613 \\
\hline & Absent & 1 & & \\
\hline Age & & 0.03 & -0.74 to 1.30 & 0.585 \\
\hline Pain intensity & & 0.07 & 0.03 to 0.11 & 0.002 \\
\hline Duration of pain episode & & -0.01 & -0.03 to 0.02 & 0.747 \\
\hline Sleep satisfaction & & -0.03 & -0.07 to 0.01 & 0.137 \\
\hline Days of work loss & & 0.15 & 0.05 to 0.24 & 0.003 \\
\hline Psychological wellbeing & & -0.10 & -0.16 to -0.03 & 0.004 \\
\hline
\end{tabular}

$a R^{2}=0.407, \beta=$ beta coefficient, $\mathrm{Cl}=$ confidence interval

disability, while longer work absence, BBDS and not consuming alcohol were associated with greater disability. Our findings provided context-specific evidence to guide priority setting in prevention and treatment strategies to reduce the burden of low back pain. Larger and robust population-based studies are warranted to fine-tune our findings.

\section{Acknowledgements}

We thank the staff at the Rheumatology Unit for their cooperation during this study and especially the study participants for accepting to take part in the study.

\section{Funding}

None.

Availability of data and materials

Data are available on reasonable request from corresponding author.

\section{Authors' contributions}

Study conception and design: JA, LNA, MDB, AMC, and FLK. Data collection: $J A, M D B, F K L, F M K$. Statistical analysis: JA and LNA. Drafting of manuscript: JA and LNA. Critical review of manuscript: MDB, LNA, JA, AMC, EVY. All authors read and approved the final manuscript.

\section{Authors' information}

Marie Doualla Bija: Associate Professor of Internal Medicine and Rheumatology, Faculty of Health Sciences, University of Buea, and Consultant Internist-Rheumatologist, Douala General Hospital, Cameroon.

Jeannine Aminde: Physician, Etoug-Ebe Baptist Hospital, Yaounde, and Faculty of Health Sciences, University of Buea, Cameroon.

Leopold Ndemnge Aminde: Physician and Doctoral candidate, Faculty of Medicine, School of Public Health, University of Queensland, Australia. Fernando Kemta Lekpa: Consultant Internist-Rheumatologist, Douala General Hospital, and Lecturer, Faculty of Health Sciences, University of Buea, Cameroon.

Felix Mangan Kwedi: Consultant Internist-Rheumatologist, Douala General Hospital, and Lecturer, Faculty of Medicine \& Pharmaceutical Sciences, University of Douala, Cameroon. 
Emmanuel Vubo Yenshu: Professor of Sociology at the Department of Sociology \& Anthropology, and Dean of the Faculty of Social and Management Sciences, University of Buea, Cameroon.

Alain Mefire Chichom: Associate Professor of Surgery and Head of Department of Surgery, Faculty of Health Sciences, University of Buea. Consultant General Surgeon, Gyneco-Obstetric and Paediatric Hospital Douala, Cameroon.

\section{Ethics approval and consent to participate}

All the patients read and signed an informed consent sheet. Research authorisations were obtained from the administration of Douala General Hospital. Ethical clearance was obtained from the Faculty of Health Sciences Institutional Ethical Review Board of the University of Buea, Cameroon.

\section{Consent for publication}

NA

\section{Competing interests}

All authors declare no conflict of interest.

\section{Publisher's Note}

Springer Nature remains neutral with regard to jurisdictional claims in published maps and institutional affiliations.

\section{Author details}

${ }^{1}$ Faculty of Health Sciences, University of Buea, Buea, Cameroon. ${ }^{2}$ Faculty of Medicine and Pharmaceutical Sciences, University of Douala, Douala, Cameroon. ${ }^{3}$ Douala General Hospital, Douala, Cameroon. ${ }^{4}$ Faculty of Social \& Management Sciences, University of Buea, Douala, Cameroon. ${ }^{5}$ Faculty of Medicine, School of Public Health, The University of Queensland, Brisbane, Australia.

Received: 27 March 2018 Accepted: 4 January 2019

Published online: 15 January 2019

\section{References}

1. Chou R. Low back pain (chronic). BMJ Clin Evid. 2010;10:1116.

2. Hoy D, Bain C, Williams $G$, et al. A systematic review of the global prevalence of low back pain. Arthritis Rheum. 2012;64:2028-37.

3. Meucci RD, Fassa AG, Faria NMX. Prevalence of chronic low back pain: systematic review. Rev Saúde Pública. 2015;49:1.

4. Louw QA, Morris LD, Grimmer-Somers K. The prevalence of low back pain in Africa: a systematic review. BMC Musculoskelet Disord. 2007;8:105.

5. National Center for Health Statistics (US). Health, United States, 2015: with special feature on racial and ethnic health disparities. In: Hyattsville (MD) National Center for Health Statistics (US); 2016.

6. Lekpa FK, Doualla MS, Singwe-Ngandeu M, et al. AB0847 non-specific chronic low Back pain is common in sub-Saharan Africa: a hospital-based study in Cameroon. Ann Rheum Dis. 2016;75:1192-2.

7. Chou R. Diagnosis and treatment of low Back pain: a joint clinical practice guideline from the American College of Physicians and the American pain society. Ann Intern Med. 2007;147:478.

8. GBD 2015 Disease and Injury Incidence and Prevalence Collaborators. Global, regional, and national incidence, prevalence, and years lived with disability for 310 diseases and injuries, 1990-2015: a systematic analysis for the Global Burden of Disease Study 2015. Lancet Lond Engl. 2016;388:1545-602.

9. World Health Organization. International classification of impairments, disabilities, and handicaps: a manual of classification relating to the consequences of disease, published in accordance with resolution WHA29. 35 of the twenty-ninth world health assembly, May 1976. Geneva: World Health Organization; 1980. http://www.who.int/iris/handle/10665/41003

10. Antunes RS, de Macedo BG, Amaral T d S, et al. Pain, kinesiophobia and quality of life in chronic low back pain and depression. Acta Ortop Bras. 2013;21:27-9.

11. Galukande M, Muwazi S, Mugisa BD. Disability associated with low back pain in Mulago hospital. Kampala Uganda Afr Health Sci. 2006;6:173-6.

12. Brouwer S, Dijkstra PU, Stewart RE, et al. Comparing self-report, clinical examination and functional testing in the assessment of work-related limitations in patients with chronic low back pain. Disabil Rehabil. 2005;27: 999-1005.
13. Smeets RJEM, Van Geel AC, Kester AD, et al. Physical capacity tasks in chronic low back pain: what is the contributing role of cardiovascular capacity, pain and psychological factors? Disabil Rehabil. 2007;29:577-86.

14. Kuijer W. Measuring disability in patients with chronic low back pain: the usefulness of different instruments. S.n., 2006. 185p.

15. Mbada CE, Idowu OA, Ogunjimi OR, et al. Cross-cultural adaptation, reliability and validity of the Yoruba version of the Roland Morris disability questionnaire. Spine. 2016;42:497-503.

16. Martin R, Jeremy F. The Roland-Morris disability questionnaire and the Oswestry disability questionnaire. Spine. 2000;25:3115-24.

17. Chiarotto A, Maxwell $\sqcup$, Terwee $C B$, et al. Roland-Morris disability questionnaire and Oswestry disability index: which has better measurement properties for measuring physical functioning in nonspecific low Back pain? Systematic review and meta-analysis. Phys Ther. 2016;96:1620-37.

18. Smeets R, Köke A, Lin C-W, et al. Measures of function in low Back pain/ disorders: low Back pain rating scale (LBPRS), Oswestry disability index (ODI), progressive Isoinertial lifting evaluation (PILE), Quebec Back pain disability scale (QBPDS), and Roland-Morris disability questionnaire (RDQ). Arthritis Care Res. 2011:63:S158-73.

19. Garbi M de OSS, Hortense P, Gomez RRF, et al. Pain intensity, disability and depression in individuals with chronic back pain1. Rev Lat Am Enfermagem. 2014;22:569-75

20. Stefane T, Santos AM dos, Marinovic A, et al. Chronic low back pain: pain intensity, disability and quality of life. Acta Paul Enferm 2013; 26: 14-20.

21. Al-disoki SSE, Yassin M, El-Ghoul, et al. Prevalence of low Back pain and its effect on quality of life among patients attending Abokhalefa center, Ismailia governorate. Med J Cairo Univ. 2015;83:385-94.

22. Schiphorst Preuper HR, Reneman MF, Boonstra AM, et al. Relationship between psychological factors and performance-based and self-reported disability in chronic low back pain. Eur Spine J. 2008;17:1448-56.

23. Huxel Bliven KC, Anderson BE. Core stability training for injury prevention. Sports Health. 2013:5:514-22

24. Cho KH, Beom JW, Lee TS, et al. Trunk muscles strength as a risk factor for nonspecific low Back pain: a pilot study. Ann Rehabil Med. 2014;38:234-40.

25. Zende D, Shimpi A, Revedkar M, et al. Correlation of low Back pain with Core muscle strength in Primigravida Indian females. Int J Health Rehabil Sci. 2014;3:19-23.

26. Sezgin M, Hasanefendioğlu EZ, Sungur MA, et al. Sleep quality in patients with chronic low back pain: a cross-sectional study assesing its relations with pain, functional status and quality of life. J Back Musculoskelet Rehabil. 2015:28:433-41.

27. George SZ, Beneciuk JM. Psychological predictors of recovery from low back pain: a prospective study. BMC Musculoskelet Disord. 2015;16:49.

28. Marty M, Rozenberg S, Duplan B, et al. Quality of sleep in patients with chronic low back pain: a case-control study. Eur Spine J. 2008;17:839-44.

29. Altuğ F, Ünal A, Kilavuz $G$, et al. Investigation of the relationship between kinesiophobia, physical activity level and quality of life in patients with chronic low back pain 1. J Back Musculoskelet Rehabil. 2016;29:527-31.

30. Jensen OK, Nielsen CV, Stengaard-Pedersen K. One-year prognosis in sicklisted low back pain patients with and without radiculopathy. Prognostic factors influencing pain and disability. Spine J. 2010;10:659-75.

31. Williams JS, Ng N, Peltzer K, et al. Risk factors and disability associated with low Back pain in older adults in low- and middle-income countries. Results from the WHO study on global AGEing and adult health (SAGE). PLoS One. 2015;10:e0127880

32. Institut National de la Statistique. Chapitre 4 : Caractéristiques de la population, Annuaire Statistique du Cameroun 2015. Yaoundé: Institut National de la Statistique; 2016

33. Lauridsen $\mathrm{HH}$, Hartvigsen J, Manniche C, et al. Responsiveness and minimal clinically important difference for pain and disability instruments in low back pain patients. BMC Musculoskelet Disord. 2006;7:82

34. Stratford PW, Riddle DL. A Roland Morris disability questionnaire target value to distinguish between functional and dysfunctional states in people with low Back pain. Physiother Can. 2016;68:29-35.

35. Kamper SJ, Maher CG, Herbert RD, et al. How little pain and disability do patients with low back pain have to experience to feel that they have recovered? Eur Spine J. 2010;19:1495-501.

36. Deyo RA, Dworkin SF, Amtmann D, et al. Report of the NIH task force on research standards for chronic low Back pain. Phys Ther. 2015;95:e1-e18.

37. de Vet HC, Heymans MW, Dunn KM, et al. Episodes of low Back pain: a proposal for uniform definitions to be used in research. ResearchGate. 2002; 27:2409-16. 
38. World Health Organization. Division of mental health. WHOQOL-BREF: introduction, administration, scoring and generic version of the assessment : field trial version. Geneva: World Health Organization; 1996. p. 1996. http:// www.who.int/iris/handle/10665/63529

39. Horng Y-S, Hwang Y-H, Wu H-C, et al. Predicting health-related quality of life in patients with low Back pain. ResearchGate. 2005;30:551-5.

40. Gavira Pavón A, Walker Chao C, Rodríguez Rodríguez N, et al. Prevalence and risk factors of urinary incontinence in women who visit the doctor with low back pain: multicentre study. Aten Primaria. 2014;46:100-8.

41. Kim H, Yoshida $\mathrm{H}, \mathrm{Hu}$ X, et al. Association between self-reported urinary incontinence and musculoskeletal conditions in community-dwelling elderly women: a cross-sectional study. Neurourol Urodyn. 2015;34:322-6.

42. Okokon IB, John EE, Udonwa NE, et al. Correlates and predictors of low Back pain disability and its impact on health- related quality of life in a family practice Clinic in Calabar, south- South Nigeria. Fam Med Med Sci Res. 2016:1-9.

43. Salvetti M de G, Pimenta CA de M, Braga PE, et al. Disability related to chronic low back pain: prevalence and associated factors. Rev Esc Enferm USP. 2012;46:16-23.

44. Parmelee PA, Tighe CA, Dautovich ND. Sleep disturbance in osteoarthritis: linkages with pain, disability and depressive symptoms. Arthritis Care Res. 2015;67:358-65.

Ready to submit your research? Choose BMC and benefit from:

- fast, convenient online submission

- thorough peer review by experienced researchers in your field

- rapid publication on acceptance

- support for research data, including large and complex data types

- gold Open Access which fosters wider collaboration and increased citations

- maximum visibility for your research: over $100 \mathrm{M}$ website views per year

At BMC, research is always in progress.

Learn more biomedcentral.com/submissions 